\title{
From Ancient to Modern: The role of astronomy as a cultural experience
}

\author{
Margaret Austin \\ Royal Society of New Zealand, \\ PO Box 598, Wellington 6140, New Zealand \\ email: austinme@xtra.co.nz
}

Ata Whakararongo ake e moko

Ki enei korero

$\mathrm{O}$ ou matua tupuna

I haere ta whiti mai ki tata
Listen carefully child

To these words of your grandparents

That have come from afar

Tena koutou, tena koutou, tena koutou katoa†

With these sung words a grandmother, a teacher of the Waitaha Maori people of New Zealand, sets in motion the telling of the great patterns of journeys. These journeys to and from distant shores are still in the minds and memories of the elder grandparent teachers of the Waitaha people.

It is impossible to convey to you the enormous privilege it is to be here to speak with the permission of the Waitaha grandmothers of today and to tell you something of the reverence with which they relate to Astronomy. So I have come with their stories, from the ends of the earth to put the small community of 450 people at Tekapo and its Observatory on the world stage.

First though, in line with Maori tradition and protocol, I need to tell you something of my whakapapa, my genealogy. My maternal and paternal grandparents migrated from Ireland in the 1870s, met and married in New Zealand and never returned to the land of their birth. What they brought with them was a culture of hard work and a commitment to the education of their children in the land of opportunity. We are a multicultural people with a bicultural heritage. We belong to the Pacific - it permeates our being. This was reinforced a few weeks ago at the time of the tragic loss of life at Perpignan when an AirNZ plane went down. When the tail piece of the aircraft was raised New Zealanders saw the Koru, the symbol of new life, growth, strength and peace and the unfurling of the fern frond and we cried. We did not see the tail piece - we saw the symbolic Koru.

The child of the Waitaha sitting at the feet of the grandmothers was told of the tides of the universe, the journeys of the regular night visitors, the anticipated visitors, the

$\dagger$ Greetings, greetings to you all ! 
names of the stars, the constellations in and across the 36 houses they had divided the night sky into. The Waitaha are an ancient, peaceful, gentle people of the South Island believed to have lived in Aotearoa for over 1000 years and probably longer.

The elders remembered the many visits of the great glowing fireball traveler Tahana Rerenga o Io, Halley's Comet, in the night sky as it passed over their old homeland before they made the series of long journeys to the islands in the South Pacific we call Aotearoa, New Zealand. They had kept their records and their timed observations for future teaching and continue to do so.

They spoke of the return of this visitor every 75 or 76 turns of the "Earth Grandmother" around the Sun, and these events linked with lines of ancestral descent - with three generations between visits that provided time sequences so important to enable remembrance of past events. They taught that the star group Te Kupenga a Te Ao, Orion, was central to all weather and safe travel in their new world. They taught that the arrival of Matariki, Pleiades, low in the eastern sky in early June signaled the beginning of their new year and that the counting of the full moons recommenced to set the times for planting and for the making of safe journeys across the mountains or the seas. To these ancient people and now the last of their descendants the observation of the night sky is still of great importance as they realize the growing need to share the centuries of accumulated knowledge held by the last teachers with their children.

These three stories from Waitaha illustrate for you just how significant it is to hold fast to the pristine state of the night sky in the high country of the central South Island of New Zealand in an area where these ancient people had assembled on a seasonal basis for food gathering and to observe and record night sky events.

Our lives are full of meaning and myth and for the indigenous peoples in particular, cultures are centred on the spirit. Pacific peoples navigated by the stars, judged distance by the stars, understood which birds inhabited the islands and planted their crops by them. Their knowledge has been transmitted through the generations which gives it a legitimacy which we must respect. So it was that I went to the Waitaha people of the South Island of New Zealand for permission to tell you just a little of their tradition.

But there is more. Astro-navigation allowed Maori to make long sea voyages and settle in Aotearoa. They developed a rich mythology based on Rangi the sky father; Papa the earth mother; Te Ra the sun; Te Marama the Moon and Nga Whetu the stars all of which gave life its meaning even to this day.

Few nations can claim as New Zealand can that astronomy was pivotal to its founding and the principal motivation which led to exploration and eventual European settlement of the land. Captain James Cook first came to New Zealand in 1769 after observing the Transit of Venus for no other reason that to find it, map it, and later to make extensive astronomical observations for determining latitude and longitude. He came three times in all bringing explorers, astronomers, botanists and regretfully warriors.

In the early days the founding father of New Zealand Science was James Hector, geologist, weather forecaster, surveyor, botanist, founder of the New Zealand Institute, the forerunner of the Royal Society of New Zealand of which I am a Vice-President. He 
standardised time at 11hours 30 minutes ahead of Greenwich Mean Time and founded the Dominion Observatory all of this within the timeframe of 35 years.

The University of Canterbury and later the University of Auckland have been at the forefront of modern astronomical research. With pristine night skies, even in urban environments there has always been enthusiastic amateur astronomers who have distinguished themselves. Gifford interpreted the lunar landscape, Grigg pioneered astronomical photography; McIntosh observed meteor showers and orbits, Bateson variable stars, Jones co-discovered supernova 1987A in the Large Magellanic Cloud and a comet in 1946. Today the Royal Astronomical Society of New Zealand has 26 Affiliated Societies and more than 600 active members.

Professional astronomers included the New Zealander Sir William Pickering - the father of rocket science and space exploration including the mariner probes to Venus; Beatrice Tinsley, known as the Queen of the Cosmo and although I did not meet her she was a contemporary of mine at the University of Canterbury; Richard Hall's interest in the Babylonians eventually led him to build Stonehenge Aotearoa in the North Island. There are over one hundred, active, living NZ astronomers on the web and extraordinary interest among undergraduate and graduate students two of whom are present at this conference.

At the present time research and teaching of Astronomy is principally located at the University of Canterbury where there are seven academics with a wide range of interests including Professor John Hearnshaw. There is significant collaboration with the University of Auckland where Professor Phil Yock and his students are very much involved in the MOA project which is a joint project of the two Universities and Nagoya University in Japan.

The major centre for the research is University of Canterbury Observatory at Mt John just $2 \mathrm{~km}$ from Lake Tekapo and where there are now four reflecting telescopes engaged in high resolution spectroscopy, variable and binary stars, gravitational microlensing and asteroid research. The University of Canterbury is also a partner in the Southern African Large Telescope project. All of this leads us to be able to say with some confidence that the future of Astronomy in New Zealand is bright. We have come a long way from the 19th century, from navigation to mapping, from time-keeping to measuring star velocities with precision and now with advanced instruments and committed researchers we believe the door is open through astrophysics to major new discoveries.

The significance of this conference cannot be overestimated for the peoples of the world and especially for those of us in the South Pacific. For Tekapo to be recognised as a StarLight Reserve along with others would be welcomed and have far reaching significance. I have outlined the facilities and nature of the research already underway. But there is much more. The interest in the educational opportunities has captured the attention of the public, school and tertiary students. Already a group of Wellington College students have won a major award for a video they made on their time at Mt John.

An average of more than 3000 people a day pass through Tekapo in buses, cars and caravans. Many visit the Observatory at night and in daytime and are entranced with what they are able to learn, see and do; and then for Maori, and those interested in Maori culture, there is the history and knowledge of the area and their understanding of the regular cycles of the stars dominating life. 
Finally we are extremely fortunate in having the vision of the Mackenzie District Council who put in place the ordinances to protect the night sky as long ago as 1981 and which as far as we can determine are within the framework of those in the proposed Concept Document. I bring you greetings from Graeme Murray, Professor John Hearnshaw, and all who have been involved in supporting the proposal including the Mackenzie District Council. Our dream lies in the Concept Document which I trust will be adopted by the conference.

I will conclude with the words every child in New Zealand learns: Ka kite ano, see you soon! 